\title{
Advanced Vehicle Testing Activity Benchmark Testing of the Chevrolet Volt Onboard Charger
}

Richard "Barney" Carlson

April 2012

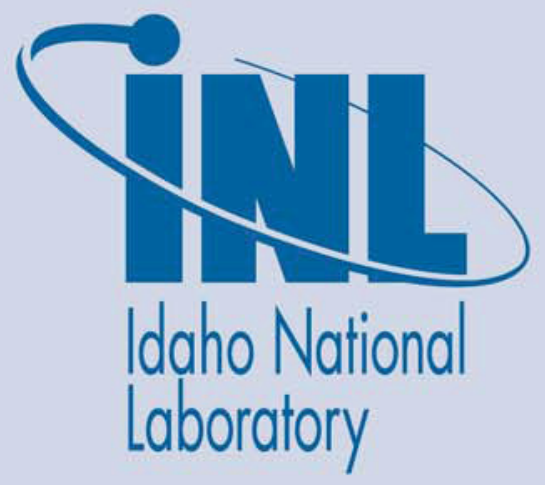

The INL is a U.S. Department of Energy National Laboratory operated by Battelle Energy Alliance 


\section{DISCLAIMER}

This information was prepared as an account of work sponsored by an agency of the U.S. Government. Neither the U.S. Government nor any agency thereof, nor any of their employees, makes any warranty, expressed or implied, or assumes any legal liability or responsibility for the accuracy, completeness, or usefulness, of any information, apparatus, product, or process disclosed, or represents that its use would not infringe privately owned rights. References herein to any specific commercial product, process, or service by trade name, trade mark, manufacturer, or otherwise, does not necessarily constitute or imply its endorsement, recommendation, or favoring by the U.S. Government or any agency thereof. The views and opinions of authors expressed herein do not necessarily state or reflect those of the U.S. Government or any agency thereof. 


\title{
Advanced Vehicle Testing Activity Benchmark Testing of the Chevrolet Volt Onboard Charger
}

\author{
Richard "Barney" Carlson
}

April 2012

Idaho National Laboratory Idaho Falls, Idaho 83415

http://avt.inel.gov

Prepared for the

U.S. Department of Energy

Office of Nuclear Energy

Under DOE Idaho Operations Office

Contract DE-AC07-05ID14517 


\section{SUMMARY}

The Chevrolet Volt onboard charge module, which converts alternating current (AC) power into direct current (DC) power to charge the vehicle's onboard energy storage system, was benchmark tested for AC to DC efficiency by the Idaho National Laboratory as part of its conduct of the U.S. Department of Energy's Advanced Vehicle Testing Activity. Charging with Level 2 electric vehicle supply equipment (EVSE) at 208 VAC input $(60 \mathrm{~Hz})$, the Volt onboard charge module was calculated to be $91.7 \%$ efficient while operating between $3.0 \mathrm{AC} \mathrm{kW}$ and $3.3 \mathrm{AC}$ $\mathrm{kW}$. Charging with Level 1 EVSE at $120 \mathrm{VAC}$ input $(60 \mathrm{~Hz})$ the Volt onboard charge module was calculated to be $90.6 \%$ efficient while operating near $1.3 \mathrm{AC} \mathrm{kW}$. Given that most Level 2 EVSE are greater than $99 \%$ efficient ${ }^{1}$ when operating above $3.0 \mathrm{AC} \mathrm{kW}$ (Level 2) and a Level 1 EVSE was measured to be $98 \%$ efficient $^{2}$ when operating above $1.25 \mathrm{AC}$ $\mathrm{kW}(120 \mathrm{VAC})$, the average overall AC to DC charging efficiency for the Chevrolet Volt connected to an EVSE (from the AC grid through the EVSE and the Volt's onboard charge module OBCM) is $90.8 \%$ for Level 2 and $88.8 \%$ for Level 1 . 


\section{CONTENTS}

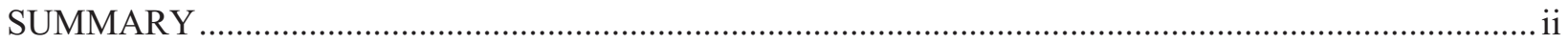

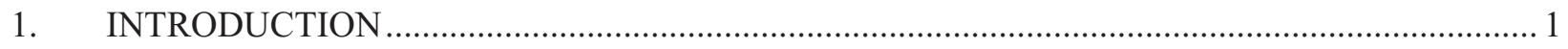

2. OVERVIEW OF THE ONBOARD CHARGER …................................................................ 1

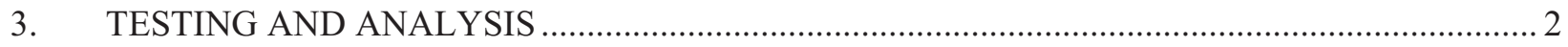

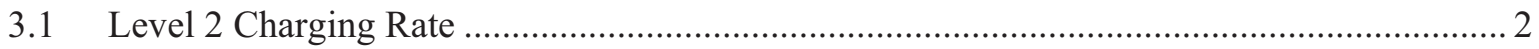

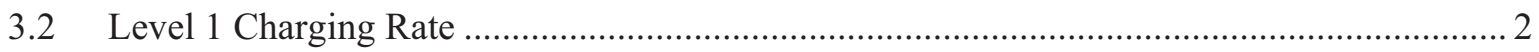

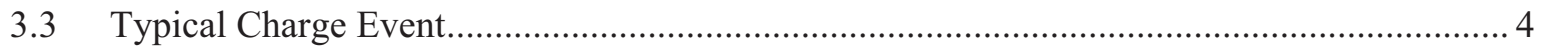

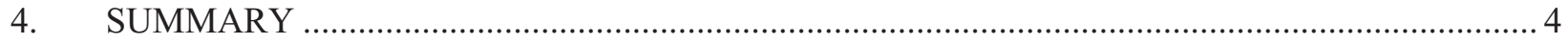

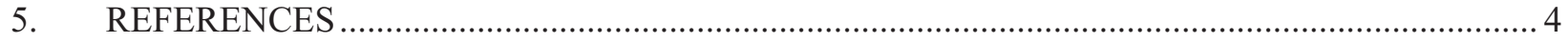

\section{FIGURES}

1. Schematic of the charging system of the Chevrolet Volt, including the electric vehicle

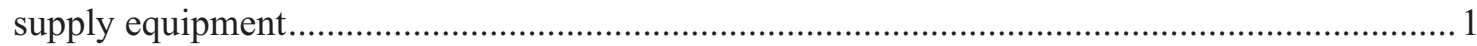

2. Volt onboard charge module efficiency at various power levels operating on 208 VAC ........... 3

3. Volt onboard charge module efficiency at various power levels operating on 120 VAC ............ 3

\section{TABLES}

1. Specifications of the onboard charge module ${ }^{3}$ 2 


\section{Advanced Vehicle Testing Activity Benchmark Testing of the Chevrolet Volt Onboard Charger}

\section{INTRODUCTION}

The Idaho National Laboratory tests advanced technology vehicles as part of its conduct of the U.S. Department of Energy's Advanced Vehicle Testing Activity (AVTA). AVTA is part of the U.S. Department of Energy's Vehicle Technologies Program. AVTA benchmarking includes grid connected vehicles and the electric vehicle supply equipment (EVSE) utilized by the vehicles for charging. This report discusses AVTA benchmark testing and analysis of the Chevrolet Volt onboard charger when operating at Level 1 and Level 2 power levels.

The efficiency of the Chevrolet Volt onboard charger was tested by measuring the input and output power during charging. The purpose of the testing is to document the results for use as reference of onboard chargers as it is one of the few production original equipment manufacturer grid-connected vehicles currently available for purchase in the United States. The testing was conducted on a 2012 Chevrolet Volt using production Level 2 EVSE and Level 1 EVSE supplied with the Volt (stored in the trunk). Efficiency was determined from measurement of the power output of the onboard charger in comparison to the input power of the onboard charger.

\section{OVERVIEW OF THE ONBOARD CHARGER}

The onboard charge module $(\mathrm{OBCM})$ receives $60 \mathrm{~Hz}$ alternating current $(\mathrm{AC})$ power from the EVSE through the SAE J1772 port on the front driver's side of the Chevrolet Volt. The OBCM is compatible with $120 \mathrm{VAC}$ and 208/240 VAC and has one input (60Hz AC) and two outputs (high and low-voltage direct current [DC]) as shown in Figure 1. While connected to EVSE with the "key off," the OBCM supplies power to the vehicle's high-voltage energy storage system (ESS), as well as the 12 VDC battery. With the "key on" while connected to EVSE, the 12 VDC power is no longer supplied by the OBCM; 12 VDC power is supplied by an onboard DC/DC converter (i.e., accessory power module) that receives its power from the ESS. ${ }^{3}$ These specifications of the OBCM are shown in Table 1.

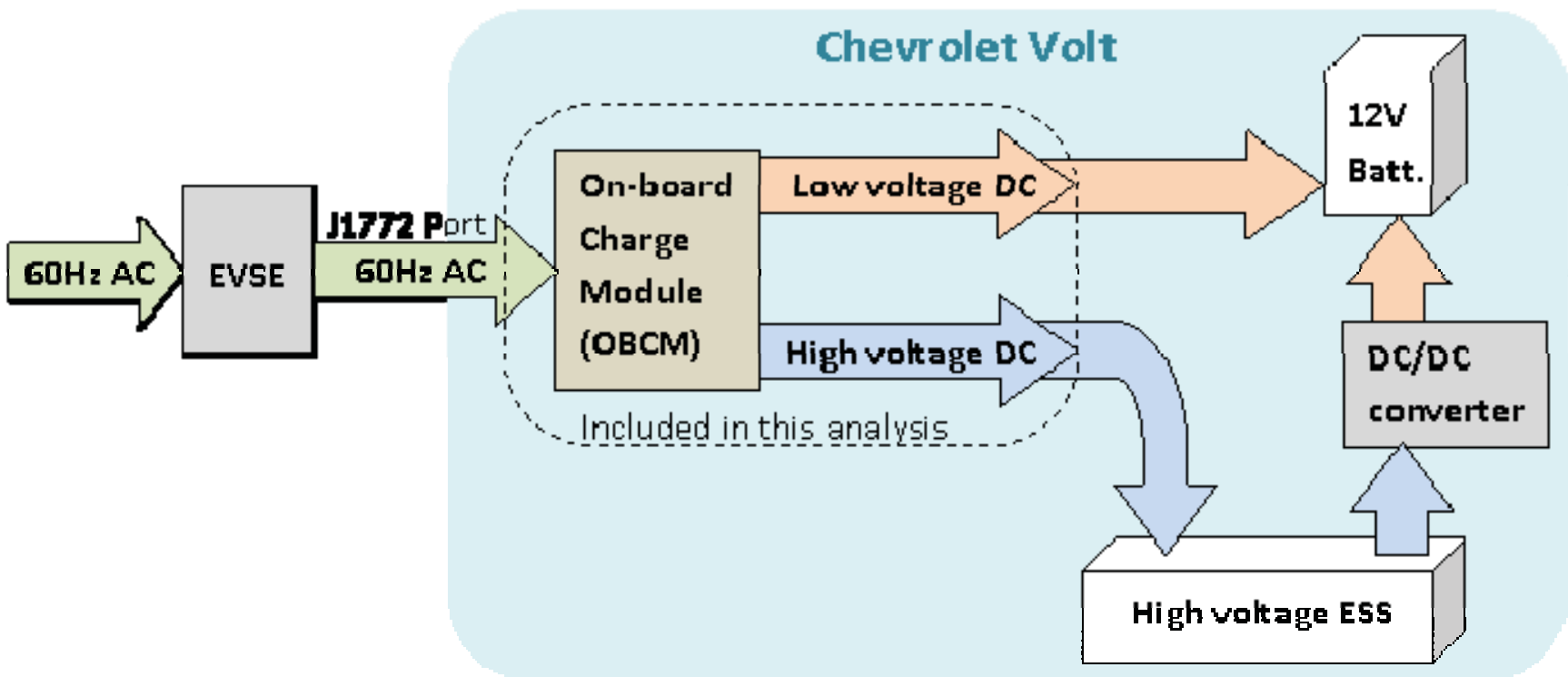

Figure 1. Schematic of the charging system of the Chevrolet Volt, including the electric vehicle supply equipment. 
Table 1. Specifications of the onboard charge module. ${ }^{3}$

\begin{tabular}{|l|l|}
\hline 12-VDC output, maximum DC current about 35A & $0.4 \mathrm{~kW}$ maximum \\
\hline High-voltage DC output with 240-VAC input & $3.3 \mathrm{~kW}$ maximum \\
\hline High-voltage DC output with 120-VAC input & $1.2 \mathrm{~kW}$ maximum \\
\hline
\end{tabular}

\section{TESTING AND ANALYSIS}

To benchmark the Volt's OBCM, measurements were taken on the input (60-Hz AC) current and voltage along with DC output current and voltage of both high-voltage output to the ESS and low-voltage output to the $12-\mathrm{V}$ battery. The high-voltage system is nominally 350 to $390 \mathrm{VDC}$, depending on state of charge, and the low-voltage system is nominally 12 VDC. These signals were obtained from CAN messages transmitted within the Volt and, for this testing, were recorded by a commercial CAN data acquisition device specifically programmed with Chevrolet Volt CAN message protocols.

\subsection{Level 2 Charging Rate}

Benchmark testing was conducted and efficiency was calculated for three scenarios: (1) charging with the "key off," (2) charging with the "key on," and (3) low-voltage charging only with the "key off" after the ESS is fully charged. When charging with the "key off" above $3.0 \mathrm{AC} \mathrm{kW}$ on $208 \mathrm{VAC}$, the average efficiency is calculated to be $91.7 \%$ (shown in Figure 2). This calculation is the combined output DC power (high voltage and low voltage) divided by the input AC power. As the charge power decreases when nearing the end of charging (at high state of charge) the efficiency also decreases. The $12-\mathrm{V}$ charging efficiency was calculated for the low voltage output from the OBCM for the "key off" condition after completion of ESS charging (ESS fully charge). As seen in Figure 2, the 12-V charging efficiency is between 50 and $75 \%$ when charging between 0.1 to $0.3 \mathrm{AC} \mathrm{kW}$. The maximum power of $0.4 \mathrm{~kW}$ (shown in Table 1) was not achieved during this testing, but the results indicate a trend of higher efficiency at higher charge rates. While charging with the "key on," the OBCM is only supplying high-voltage output power. Figure 2 shows a slighter higher efficiency for this "key on" charging as compared to "key off" charging. This is a result of the $12-\mathrm{V}$ charging (lower efficiency) being active and included in the "key off" efficiency results. It should be noted that during the "key on" charging, the DC/DC converter provides the necessary $12-\mathrm{V}$ power to accessories and to charge the $12-\mathrm{V}$ battery. The efficiency of the DC/DC converter is not included in this analysis or in Figure 2.

From previous benchmark testing efforts of the Volt charging with a production Level2 EVSE, ${ }^{1}$ the power factor was measured to be 0.997 at $3.2 \mathrm{~kW}$ and a nearly linear decrease to 0.985 at $1.0 \mathrm{~kW}$. With a power factor greater than 0.985 across the typical range of operation for a Level 2 charge event, the real power and apparent power are assumed to be essentially equal.

\subsection{Level 1 Charging Rate}

When charging above $1.25 \mathrm{AC} \mathrm{kW}$ on $120 \mathrm{VAC}$, the average efficiency was calculated to be $90.6 \%$ (shown in Figure 3). This calculation is the combined output DC power (high voltage and low voltage) divided by the input AC power. At the end of a charge event, the charge power decreases very quickly (only a few seconds). As with the Level 2 charging, the efficiency decreases as charge power decreases. The 12-V charging efficiency was calculated for the low-voltage output from the OBCM for the "key off" condition after completion of ESS charging (ESS fully charged). As seen in Figure 3, the 12-V charging efficiency is between 60 and $75 \%$ when charging at $0.15 \mathrm{AC} \mathrm{kW}$. While charging with the "key on," Figure 3 shows a slighter higher efficiency for this "key on" charging as compared to "key off" charging. As with the Level 2 charging, this is due to the $12-\mathrm{V}$ charging (lower efficiency) being active and included in the "key off" efficiency results. 


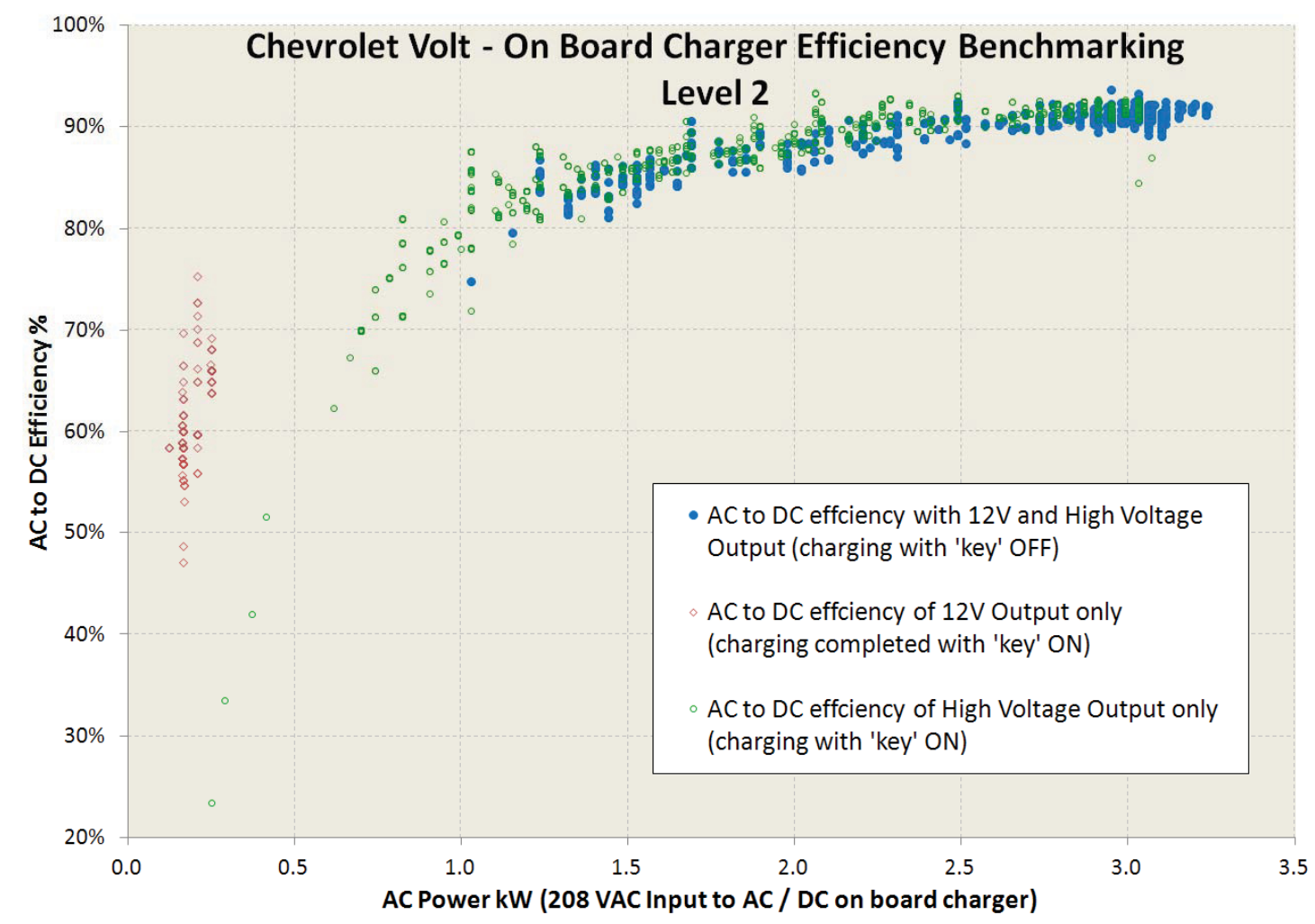

Figure 2. Volt onboard charge module efficiency at various power levels operating on 208 VAC.

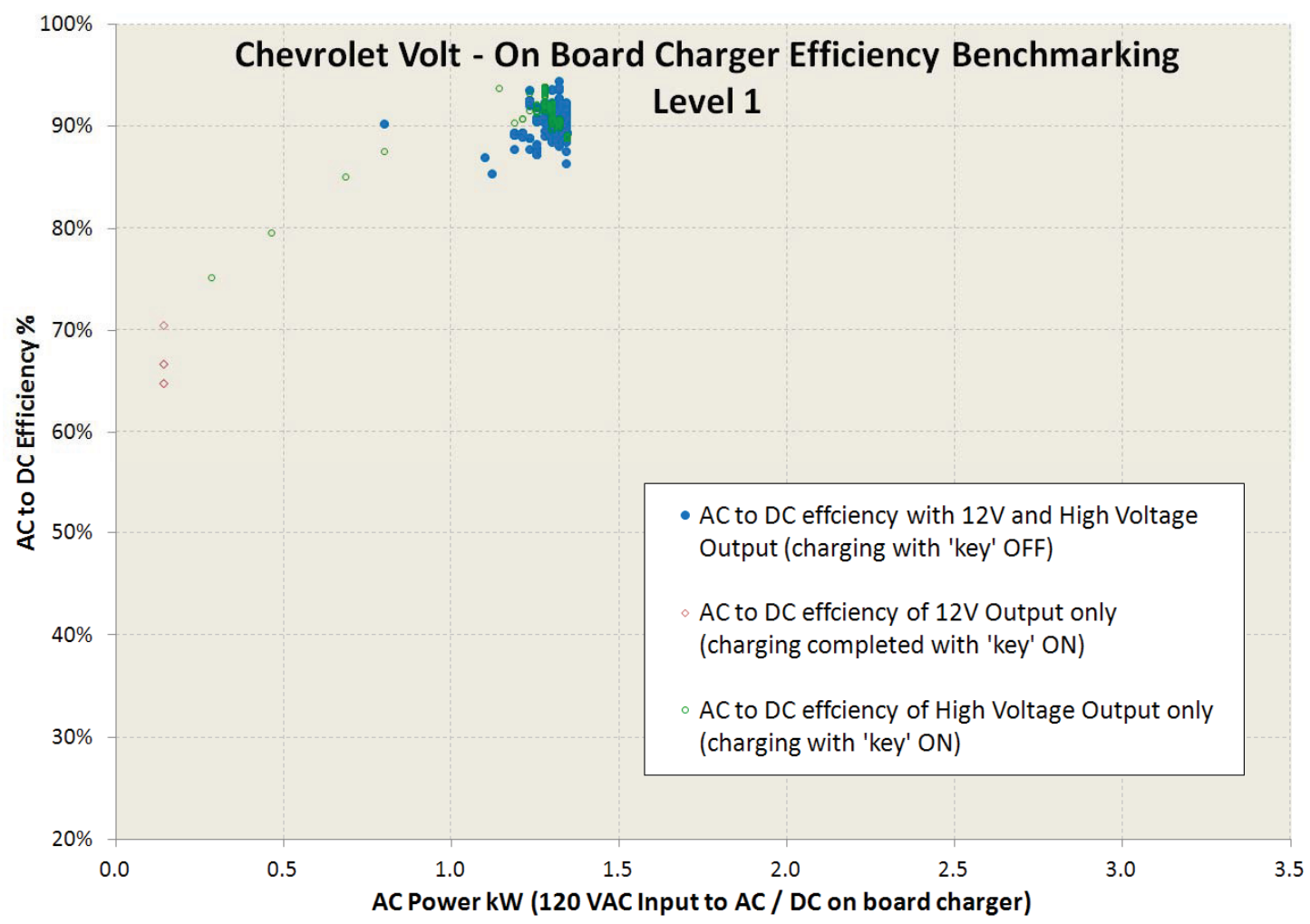

Figure 3. Volt onboard charge module efficiency at various power levels operating on 120 VAC. 


\subsection{Typical Charge Event}

During a typical charge event, full power is drawn for a majority of the time (greater than $99 \%$ of the time). For the Chevrolet Volt, full power is between 3.0 to $3.3 \mathrm{AC} \mathrm{kW}$ for Level 2 and between 1.2 and 1.4 AC kW for Level 1. This results in overall average charging efficiency being nearly the same as the full-power charging efficiency. From previous benchmark testing of EVSE ${ }^{1,2}$, it was determined that most EVSE have an operating efficiency of greater than 99\% for Level 2 EVSE and 98\% for Levell when operating near full power. Therefore, the overall charging efficiency (from the grid through the EVSE and the Volt OBCM) is $90.8 \%$ efficient between 3.0 to $3.3 \mathrm{AC} \mathrm{kW}$ when using Level 2 EVSE and $88.8 \%$ efficient above $1.25 \mathrm{AC} \mathrm{kW}$ when using Level 1 EVSE.

\section{SUMMARY}

The Chevrolet Volt OBCM was benchmark tested for AC to DC efficiency. Charging with Level 2 EVSE at 208 VAC input $(60 \mathrm{~Hz})$, the Volt onboard charger was calculated to be $91.7 \%$ efficient, operating near $3.3 \mathrm{~kW}$ with a power factor of 0.997 . Charging with Level $1 \mathrm{EVSE}$ at $120 \mathrm{VAC}$ input $(60 \mathrm{~Hz})$ the Volt onboard charger was calculated to be $90.6 \%$ efficient, operating near $1.3 \mathrm{AC} \mathrm{kW}$. Given that most Level 2 EVSE are greater than $99 \%$ efficient when operating above $3.0 \mathrm{~kW}$ (208 to $240 \mathrm{VAC}$ ) and Level 1 EVSE are 98\% efficient when operating above $1.25 \mathrm{AC} \mathrm{kW}(120 \mathrm{VAC})$, the overall AC to DC charging efficiency for the Chevrolet Volt is $90.8 \%$ for Level 2 and $88.8 \%$ for Level 1.

\section{REFERENCES / FOOTNOTES}

1. http://avt.inel.gov/evse.shtml

2. Level 1 EVSE Testing conducted in same manner as reference 1 (not yet published at the time of this document). Efficiency of the Level 1 EVSE tested is $98 \%$.

3. http://nctcog.org/trans/air/programs/evnt/ContractorInspectorOutreachTexasMay2011.pdf 